\title{
Reactive hyperemia increases forearm vein area
}

\section{[L'hyperémie réactionnelle augmente l'aire peineuse de l'avant-bras]}

Heather L. Mollison MD, ${ }^{*}$ William P.S. McKay MD FrCP, ${ }^{*}$ Rajesh H. Patel MD, $†$ Stefan Kriegler MB CHb M MED, $†$ October E. Negraeff MD*

Purpose: To determine the effect of reactive hyperemia on human forearm vein area.

Methods: After obtaining ethics approval and informed consent, an automatic tourniquet was applied to the forearms of 20 healthy subjects for one, two, and three minutes, at pressures of $25 \mathrm{mmHg}, 200 \mathrm{mmHg}$, then $25 \mathrm{mmHg}$. A blinded radiographer measured the cross-sectional area of the cephalic vein at the wrist using ultrasonography. Measurements were recorded prior to tourniquet application and every minute thereafter for ten minutes, at each pressure setting and each time interval.

Results: The mean vein cross-sectional area $\left(\mathrm{mm}^{2}\right)$ increased from $8.22 \pm 3.09$ to $10.77 \pm 3.50$ after one minute of ischemia, from $8.31 \pm 2.78$ to $10.61 \pm 2.77$ after two minutes of ischemia, and from $8.39 \pm 3.34$ to $10.94 \pm 3.46$ after three minutes of ischemia $(P<0.05$ for all). A tourniquet inflated to $25 \mathrm{mmHg}$ for 13 min produced a mean vein cross-sectional area of 10.71 $\pm 3.25 \mathrm{~mm}^{2}$.

Conclusions: Reactive hyperemia causes human forearm vein cross-sectional area to increase. A low pressure tourniquet will also increase forearm vein area, but veins dilate more quickly during reactive hyperemia. This may have important clinical implications for attempting venous cannulation in patients with difficult venous access.

Objectif : Déterminer l'effet de l'hyperémie réactionnelle sur l'aire veineuse de l'avant-bras humain.

Méthode : Ayant obtenu l'accord du comité d'éthique et le consentement éclairé des participants, nous avons appliqué un garrot automatique à l'avant-bras de 20 sujets sains pendant une, deux et trois minutes, à des pressions de $25 \mathrm{mmHg}, 200 \mathrm{mmHg}$, puis 25 $\mathrm{mmHg}$. Un radiologue impartial a mesuré, par échographie, l'aire transversale de la veine céphalique au poignet. Les mesures ont été enregistrées avant la pose du garrot et à chaque minute par la suite pendant dix minutes, pour chaque pression établie et chaque intervalle de temps.
Résultats : L'aire veineuse transversale moyenne $\left(\mathrm{mm}^{2}\right)$ a augmenté de $8,22 \pm 3,09$ à $10,77 \pm 3,50$ après une minute d'ischémie, de $8,31 \pm 2,78$ à $10,61 \pm 2,77$ après deux minutes d'ischémie et de 8,39 $\pm 3,34$ à 10,94 $\pm 3,46$ après trois minutes d'ischémie ( $P<0,05$ pour toutes les mesures). Un garrot gonflé à $25 \mathrm{mmHg}$ pendant 13 min a produit une aire veineuse transversale moyenne de $10,71 \pm 3,25 \mathrm{~mm}^{2}$.

Conclusion: L'hyperémie réactionnelle augmente l'aire veineuse transversale de l'avant-bras chez l'homme. Un garrot basse pression l'augmente aussi, mais les veines se dilatent plus rapidement pendant l'hyperémie réactionnelle. Cela pourrait avoir d'importantes implications cliniques pour les essais de canulation veineuse en cas d'accès veineux difficile.

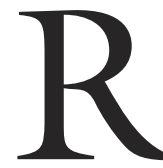

EACTIVE hyperemia is a transient increase in organ or limb blood flow following a brief period of ischemia. Numerous studa des have demonstrated the effect of reactive hyperemia on the arterial system in human limbs. Kubli et al. ${ }^{1}$ showed a fourfold increase in forearm dermal blood flow using laser Doppler imaging following the release of transient arterial occlusion. Wu et $a l^{2}$ used venous occlusive plethysmography to examine basal forearm blood flow and found that during reactive hyperemia, forearm blood flow can increase up to 3.5 times from baseline measurements. The diameter of the brachial artery has also been assessed by ultrasonography and found to increase with reactive hyperemia. ${ }^{3-5}$ Other studies have shown increases in forearm or lower limb blood flow with reactive hyperemia using different types of measurement. ${ }^{6-10}$

In contrast with a number of studies of arteries and small vessels, there are relatively few studies examining the venous response to experimental reactive

From the Departments of Anesthesia, ${ }^{*}$ and Radiology, $\dagger$ University of Saskatchewan, Saskatoon, Saskatchewan, Canada.

Address correspondence to: Dr. William P.S. McKay, Research Director and Deputy Head, Department of Anesthesia, University of Saskatchewan, Royal University Hospital, 103 Hospital Drive, Saskatoon SK S7N 0W8, Canada. Phone: 306-655-1202; Fax: 306-6551279; E-mail: william.mckay@saskatoonhealthregion.ca

This study was funded by a generous grant from the Royal University Hospital Foundation. No author has any financial connection to, or support from, any commercial interest, nor any conflict of interest resulting from participation in this study.

Accepted for publication September 1, 2005.

Revision accepted March 10, 2006. 
hyperemia. Libertiny et al. ${ }^{11}$ assessed flow velocity and popliteal vein diameter by means of colour duplex ultrasound (US) scanning in patients with peripheral vascular disease and age-matched controls. In a subset of study patients, they showed that popliteal venous diameter increases during reactive hyperemia.

If reactive hyperemia increases forearm vein crosssectional area following a standardized ischemic period, then a simple technique to facilitate placement of peripheral iv catheters may be available to clinicians. This could have clinical utility in patients with difficult venous access. Accordingly, we undertook a study to compare, under controlled conditions, the standard hospital practice of obtaining a dilated forearm vein by a low pressure tourniquet $(25 \mathrm{mmHg})$, with use of the same tourniquet pressure after one, two, or three minutes of limb ischemia (achieved at an occlusion pressure of $200 \mathrm{mmHg}$ ), to determine the clinical effects of reactive hyperemia on peripheral veins. Specifically, we tested the hypothesis that forearm venous crosssectional area will increase with tourniquet pressure of $25 \mathrm{mmHg}$ following supra-systolic occlusion (reactive hyperemia) for one, two, or three minutes compared to a tourniquet pressure of $25 \mathrm{mmHg}$ alone.

\section{Methods}

Following University of Saskatchewan Biomedical Research Ethics Board approval of the study protocol, and after obtaining informed consent, healthy adults over the age of 17 were recruited as unpaid volunteers. Subjects were excluded if they had neural or vascular limb disorders; skin disease or any disorder that would make the tourniquet painful; allergy to US gel; or if they were pregnant. Pregnant subjects were excluded because endocrine effects on the cardiovascular system may render their results non-generalizable.

A pilot study for this experiment completed by Mollison et al. ${ }^{12}$ enrolled 20 subjects, and provided statistically significant results. Prior to the pilot study, the literature was searched for data to enable a statistical power analysis to allow prediction of appropriate subject numbers $(n)$. The only article studying reactive hyperemia and vein diameter ${ }^{11}$ gives median and range, but not mean and SD. Therefore we assumed an effect difference of $2 \mathrm{~mm}$ in vein diameter and a SD of vein diameter change of $3 \mathrm{~mm}$. Using these plausible and clinically useful parameters, the experiment would detect a difference with $\alpha$ probability less than 0.05 , and avoid a $\beta$ error of greater than 0.2 , with 18 subjects. ${ }^{13}$ Therefore, for this experiment, 20 subjects were enrolled.

Standard hospital US, mercury manometer blood pressure apparatus, and automatic tourniquet were used. These are Canadian Standards Association tested and approved for patient use. There are no known biological side-effects of US when used within specifications. Room temperature was monitored throughout the experiments with an electronic thermometer (Kenmore - Sears, Roebuck, Denver, CO, USA). The US machine was an ATL 5000 HDI (Koninklijke Philips Electronics N.V., Eindhoven, the Netherlands), equipped with a $12 \mathrm{MHz}$ linear transducer. Minimal resolution specifications of this system were two decimal places of $1 \mathrm{~mm}( \pm 1 \%)$ in the axial plane, and $1 \mathrm{~mm}$ $( \pm 2 \%)$ in the lateral plane. The manufacturer reports that, in testing, the $12 \mathrm{MHz}$ transducer performs slightly better than the above numbers. One sonographer performed all of the examinations. The mercury sphygmomanometer was a Trimline model (PyMaH Corp., Somerville, NJ, USA). The automatic tourniquet was a Zimmer model ATS 2000 (Zimmer Patient Care Division, Dover, OH, USA).

Biophysical profile data were recorded. Room temperature remained steady at $22.8^{\circ} \mathrm{C}$ (range $22.2-$ $23.3^{\circ}$ ). Baseline blood pressure was measured, using the American Heart Association recommendations for routine blood pressure measurement by indirect cuff sphygmomanometry, ${ }^{14}$ with the subject sitting comfortably in a chair with arm rests. Preparatory procedures were then carried out: an automatic tourniquet was applied to both arms of each subject, and then inflated to $25 \mathrm{mmHg}$. Ultrasonography was used to identify a distal forearm cephalic vein just proximal to each wrist, and the veins were marked with a slimpoint indelible marker. All subjects then received the following experimental treatments to provide exposure to one-, two-, and three-minute inflations at 25 and at $200 \mathrm{mmHg}$ :

i- tourniquet inflated on right arm to $25 \mathrm{mmHg}$ for one minute, at which time a US image of the marked vein was recorded;

ii- tourniquet inflated on right arm to 200 $\mathrm{mmHg}$ for one minute, then deflated to 25 $\mathrm{mmHg}$ for serial US imaging at one-minute intervals for ten minutes;

iii- tourniquet inflated on left arm to $25 \mathrm{mmHg}$ for three minutes with serial US scans at 25 $\mathrm{mmHg}$ every minute for a total of ten minutes; iv- tourniquet inflated on left arm to $200 \mathrm{mmHg}$ for three minutes, then deflated to $25 \mathrm{mmHg}$ for serial US imaging at one-minute intervals for ten minutes;

$\mathrm{v}$ - tourniquet inflated on right arm to $25 \mathrm{mmHg}$ for two minutes followed by a US scan; vi- tourniquet inflated on right arm to 200 $\mathrm{mmHg}$ for two minutes, then deflated to 25 
$\mathrm{mmHg}$ for serial US imaging at one-minute intervals for ten minutes.

Pre- and postreactive hyperemia US scans were digitized, then read and measured off-line by a radiologist blinded to the treatments. The vein images were most commonly elliptical, so the long and short elliptical diameters were measured and recorded in units of pixels. Each US scan generated a calibration factor (pixels per $\mathrm{mm}$ ) that was used to transform the diameters into Système International units: length $(\mathrm{mm})$; the radii, $r_{1}$ and $r_{2}$, are half of the elliptical diameters. Area (A) was calculated by the formula:

$$
\mathrm{A}=\pi \cdot \mathrm{r}_{1} \cdot \mathrm{r}_{2}
$$

Treatments were conducted simultaneously on the subject's right and left arm to limit the time commitment for each subject to $30-45 \mathrm{~min}$.

\section{Statistical considerations}

Repeated-measures analysis of variance (ANOVA) was used to analyze continuous variables. Post hoc comparisons used $t$ tests and the true correction for multiple comparisons, ${ }^{15}$

$$
\alpha \mathrm{T}=1-(1-\alpha)^{\mathrm{k}}
$$

where $\alpha$ is the $P$-value, the probability of a result occurring by chance alone, and $\mathrm{\kappa}(=5)$ is the number of comparisons. Analysis was performed with SigmaStat for Windows version 1 (Jandel Scientific, Div. of Jandel Corp. San Rafeal, CA, USA). $P<0.05$ of a difference occurring by chance alone was considered significant.

\section{Results}

The average age was $34 \pm 9.4 \mathrm{yr}$, height $174.4 \pm 8.5$ $\mathrm{cm}$, and weight $75.4 \pm 16.8 \mathrm{~kg}$. All subjects were normotensive, and none was known to be taking any medication, including antihypertensives. The subjects in this experiment found the ischemic period mildly uncomfortable, but easily bearable.

\section{Vein area}

The maximum vein cross-sectional areas following one-, two-, and three-minute cuff inflations at 25 and 200 $\mathrm{mmHg}$, as well as prolonged $25 \mathrm{mmHg}$ tourniquet inflation, were compared to one minute values at 25 $\mathrm{mmHg}$, as a control, by repeated measures ANOVA. The Normality Test was passed $(P=0.0597)$, as was the Equal Variance Test: $(P=0.9177)$. The mean vein area $\left(\mathrm{mm}^{2}\right)$ increased from $8.22 \pm 3.09$ to $10.77 \pm$ 3.50 after one minute of ischemia, from $8.31 \pm 2.78$ to $10.61 \pm 2.77$ after two minutes of ischemia, and from $8.39 \pm 3.34$ to $10.94 \pm 3.46$ after three minutes of ischemia $(P<0.05$ for all $)$. There was no correla-

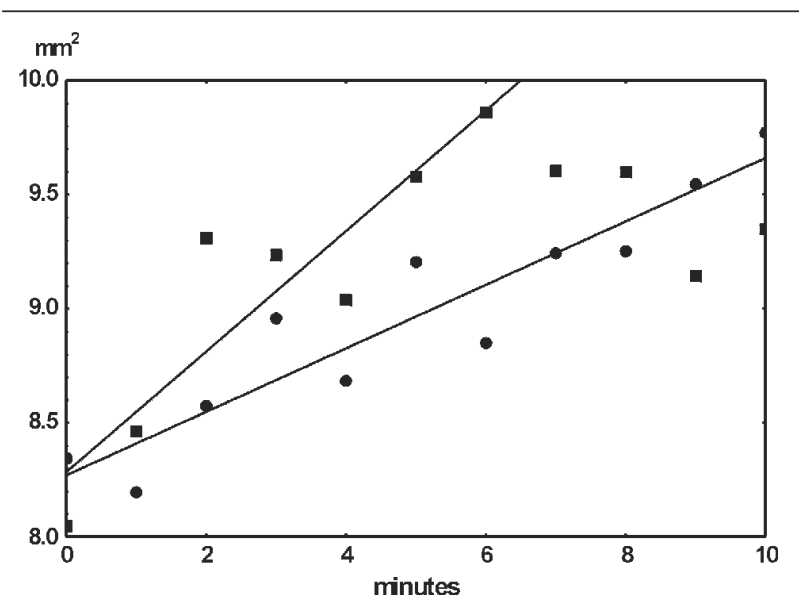

FIGURE Mean vein area $v s$ time following a three-minute tourniquet application at $25 \mathrm{mmHg}$ (round markers) or $200 \mathrm{mmHg}$ (square markers), with regression lines to maximum for each.

tion between the postischemic change and the initial vein size $(R=0.008)$.

\section{Time course of vein dilation}

Increased vein area was achieved after one, two, or three minutes of ischemia in comparison with the same periods of $25 \mathrm{mmHg}$ tourniquet exposure. Prolonged $25 \mathrm{mmHg}$ inflation, however, produced a mean maximum vein cross-sectional area of $10.71 \pm$ $3.25 \mathrm{~mm}^{2}$ after $13 \mathrm{~min}$. This maneuver was as effective as reactive hyperemia, although the maximum dilation was achieved earlier using reactive hyperemia. The Figure shows the time course of dilation to maximum vein area. Following three minutes with the tourniquet at $25 \mathrm{mmHg}$ using linear regression up to the time of maximum dilation (regression line shown), shows an increased vein area of $0.13 \mathrm{~mm}^{2} \cdot \mathrm{min}^{-1}$, giving the equation:

Area $=0.131 \times$ time +8.2 with $R=0.94$. $(P$ for constant and regression coefficient both $<0.0001$ ).

The corresponding rate following $200 \mathrm{mmHg}$ for three minutes is $0.25 \mathrm{~mm}^{2} \cdot \mathrm{min}^{-1}$, giving the equation:

Area $=0.248 \times$ time +8.1 with $R=0.92 .(P$ for constant $<0.0001$; for regression coefficient $=0.001$ ) Ninety-five percent confidence intervals for the coefficients show them to be significantly different: for three minutes at $25 \mathrm{mmHg}, 95 \%$ confidence intervals $=0.129$ to 0.133 ; for three minutes at $200 \mathrm{mmHg}$, confidence intervals $=0.238$ to 0.258 . From the Figure, it can be seen that maximal vein dilation after three minutes of ischemia occurred at six minutes, 
compared to ten minutes with the tourniquet at nonischemic pressures.

\section{Discussion}

Although numerous studies have demonstrated the effect of reactive hyperemia on the arterial system of human limbs, there is a paucity of data evaluating its effect on the venous system. This study aimed to determine the effect of reactive hyperemia on human forearm vein cross-sectional area. There are two principal interpretations from this data. First, reactive hyperemia produces a rapid increase in forearm vein cross-sectional area. The extent of venous dilation is similar whether reactive hyperemia is achieved with one-, two- or three-minute periods of ischemia. Second, maintaining a low-pressure venous tourniquet on the arm for a prolonged period of time will ultimately achieve forearm venous dilation similar to reactive hyperemia, but maximum dilation occurs sooner with reactive hyperemia.

It has been shown previously that the arterial response to an increase in blood flow during reactive hyperemia is vasodilation. ${ }^{16}$ This flow-mediated dilation is endothelium-dependent, and related to nitric oxide release. ${ }^{17}$ Patients with risk factors for atherosclerosis have reduced or absent flow-mediated arterial vasodilation during reactive hyperemia, secondary to endothelial dysfunction. ${ }^{18}$

The venous response to reactive hyperemia has not been investigated as thoroughly as the arterial response. Only one previous experiment showed an increase in the diameter of the popliteal vein during reactive hyperemia. ${ }^{11}$ The mechanism whereby this venous response occurs has not been elucidated. It may be a passive response by the capacitance vessels to increased arterial flow, or it may be an active response, possibly mediated by a similar endothelial-dependent mechanism as the arterial dilation. Unlike flow-mediated dilation in arteries, which is inversely related to baseline vessel diameter, we were unable to show a correlation between postischemic dilation and initial vein size.

An additional finding in this study was a trend toward venoconstriction prior to venodilation following ischemia. Although not statistically significant, in a related pilot study where a five-minute ischemic period was utilized, significant transient venoconstriction was demonstrated. Libertiny et al. also demonstrated a decrease in popliteal vein diameter during reactive hyperemia in a subset of their patients with peripheral vascular disease. ${ }^{11}$ They speculated that a humoral factor related to tissue ischemia may be involved in producing this venoconstriction. Similarly, when a prolonged ischemic time was utilized in the pilot project for this study, initial venoconstriction resulted. This suggests that at least the initial venous response to reactive hyperemia is an active rather than a passive response to greater inflow from the arteries.

One limitation of our study was an inability to control for factors that may influence endothelial function, such as smoking, diabetes and hypercholesterolemia. Impaired endothelial function may directly, or indirectly via the arterial response, impact the venous response to reactive hyperemia. Although we were able to show an overall effect with an increase in venous cross-sectional area during reactive hyperemia, the impact of this increase may have been compromised by including subjects with possible endothelial dysfunction.

In conclusion, reactive hyperemia produces an increase in human forearm vein area. The increase in cross-sectional area is similar whether reactive hyperemia follows a one-, two-, or three-minute ischemic period. Reactive hyperemia-induced venodilation may possibly facilitate placement of peripheral iv catheters in patients with difficult venous access. Further experimental work in this area will be undertaken to determine the optimal timing for iv catheter placement during maximal postischemic venodilation. Additionally, elucidating whether certain populations have exaggerated venodilation during reactive hyperemia may capitalize on its utility for iv cannulation.

\section{References}

1 Kubli S, Waeber B, Dalle-Ave A, Feibl F. Reproducibility of laser Doppler imaging of skin blood flow as a tool to assess endothelial function. J Cardiovasc Pharmacol 2000; 36: 640-8.

2 Wu TC, Chen $\Upsilon H$, Chen JW, et al. Impaired forearm reactive hyperemia is related to late restenosis after coronary stenting. Am J Cardiol 2000; 85: 1071-6.

3 Savvidou MD, Kametas NA, Donald AE, Nicolaides $K H$. Non-invasive assessment of endothelial function in normal pregnancy. Ultrasound Obstet Gynecol 2000; 15: 502-7.

4 Stadler RW, Ibrahim SF, Lees RS. Measurement of the time course of peripheral vasoactivity: results in cigarette smokers. Atherosclerosis 1998; 138: 197-205.

5 Kao YH, Mohler ER, Arger PH, Sehgal CM. Brachial artery: measurement of flow-mediated dilatation with cross-sectional US - technical validation. Radiology 2003; 228: 895-900.

6 Higashi $\Upsilon$, Sasaki S, Nakagawa K, Matsuura H, Kajiyama G, Oshima T. A noninvasive measurement of reactive hyperemia that can be used to assess resistance artery endothelial function in humans. Am J Cardiol 
2001; 87: 121-5.

7 Baldassarre D, Amato M, Palombo C, Morizzo C, Pustina L, Sirtori CR. Time course of forearm arterial compliance changes during reactive hyperemia. Am J Physiol (Heart Circ Physiol) 2001; 281: H1093-103.

8 Monsuez JJ, Dufaux J, Vittecoq D, Vicaut E. Reduced reactive hyperemia in HIV-infected patients. J Acquir Immune Defic Syndr 2000; 25: 434-42.

9 Matsubara J, Narumi J, Nagasue M, Sakamoto S, Yuasa $K$, Shimizu $T$. Postocclusive reactive hyperemia during vascular reconstruction. Int J Angiol 1998; 7: 222-7.

10 Schnizer W, Hinneberg H, Moser H, Kuper K. Intraand extravascular volume changes in the human forearm after static hand grip exercise. Eur J Appl Physiol Occup Physiol 1979; 41: 131-40.

11 Libertiny $G$, Hands L. Lower limb deep venous flow in patients with peripheral vascular disease. J Vasc Surg 1999; 29: 1065-70.

12 Mollison HL, McKay WP, Patel R, Chow V, Negraeff O, $\operatorname{Karam} R$. Effect of reactive hyperemia on forearm vein area - a pilot study. Can J Anesth 2004; 51(suppl): A6 (abstract).

13 Lerman J. Study design in clinical research: sample size estimation and power analysis. Can J Anaesth 1996; 43: 184-91.

14 Perloff D, Grim C, Flack J, et al. Human blood pressure determination by sphygmomanometry. Circulation 1993; 88(5 Pt 1): 2460-7.

15 Glantz $S A$. A Primer of Biostatistics, 3rd ed. New York: McGraw-Hill; 1992.

16 Anderson TJ, Uehata A, Gerhard MD, et al. Close relation of endothelial function in the human coronary and peripheral circulations. J Am Coll Cardiol 1995; 26 : 1235-41.

17 Joannides R, Haefeli WE, Linder L, et al. Nitric oxide is responsible for flow-dependent dilatation of human peripheral conduit arteries in vivo. Circulation 1995; 91: 1314-9.

18 Celermajer DS, Sorensen KE, Gooch VM, et al. Noninvasive detection of endothelial dysfunction in children and adults at risk of atherosclerosis. Lancet 1992; 340: 1111-5. 